

\title{
New Evidence on the Role of Regional Clusters and Convergence in China (1952-2008)
}

\author{
M. J. Herrerias \\ Aix-Marseille-Université, GREQAM \\ maria-jesus.herrerias@univmed.fr
}

\author{
J. Ordoñez \\ Universitat Jaume I \\ Department of Economics \\ jmonfort@eco.uji.es
}

$2011 / 07$

\begin{abstract}
A new panel method is applied to the case of Chinese provinces to analyze the existence of club convergence in terms of per capita income, labor productivity, capital intensity, and total factor productivity from 1952 to 2008 . The advantage of this approach is that it takes into account the heterogeneity of Chinese regions in a nonlinear time-varying framework, where more attention is paid to the spatial dimension. This time-varying approach outperforms other methods used in the relevant literature for an economy in transition, such as China, that has undergone a significant transformation over the period under consideration. Our results indicate that Chinese regions have converged into clubs. However, it is observed that Heilongjiang is diverging in terms of labor productivity and capital intensity, while Liaoning and Guizhou display similar patterns in terms of labor productivity, and Shanxi and Hebei in terms of capital intensity. These results indicate that specific economic packages need to be implemented in the clusters that were identified, with special attention to those regions that show a divergence behavior, in order to guarantee the sustainability and equality of regional growth.
\end{abstract}

Keywords: Endogenous Unit Root Test, Club Convergence, Chinese regions JEL Classification: C20, O18, O40, R11 


\title{
New Evidence on the Role of Regional Clusters and Convergence in China (1952-2008)
}

\author{
M.J. Herrerias \\ Aix-Marseille-Université, GREQAM
}

J. Ordoñez ${ }^{1}$

Universitat Jaume I

Department of Economics

\begin{abstract}
A new panel method is applied to the case of Chinese provinces to analyze the existence of club convergence in terms of per capita income, labor productivity, capital intensity, and total factor productivity from 1952 to 2008 . The advantage of this approach is that it takes into account the heterogeneity of Chinese regions in a nonlinear time-varying framework, where more attention is paid to the spatial dimension. This time-varying approach outperforms other methods used in the relevant literature for an economy in transition, such as China, that has undergone a significant transformation over the period under consideration. Our results indicate that Chinese regions have converged into clubs. However, it is observed that Heilongjiang is diverging in terms of labor productivity and capital intensity, while Liaoning and Guizhou display similar patterns in terms of labor productivity, and Shanxi and Hebei in terms of capital intensity. These results indicate that specific economic packages need to be implemented in the clusters that were identified, with special attention to those regions that show a divergence behavior, in order to guarantee the sustainability and equality of regional growth.
\end{abstract}

Key Words: Endogenous Unit Root Test, Club Convergence, Chinese regions JEL Classification: C20, O18, O40, R11

Corresponding author: M.J. Herrerias, Aix-Marseille-Université, GREQAM. Centre de la Vieille Charité 2, rue de la Charité 13236 Marseille cedex 02 (France). E-mail address: mariajesus.herrerias@univmed.fr.

${ }^{1}$ Email: jmonfort@eco.uji.es

The first author gratefully acknowledges financial support from the European Union, project No 218246. The second author gratefully acknowledges the financial support of CICYT project ECO2008-05908-C0201, Bancaja project P1-1B2008-46 and Generalitat Valenciana project PROMETEO/2009/098. The usual disclaimer applies. 


\section{Introduction}

The concept of economic convergence is related to the reduction of inequality between countries or regions. In recent years, there has been growing concern about increasing levels of inequality, and its spatial dimension has begun to attract considerable policy interest (Kanbur and Venables, 2005). On the one hand, an important stimulus underlying this growing literature has been the renewed interest in the empirics of growth and the relatively recent contributions on convergence and endogenous growth theory, as well as the availability of new econometric techniques and richer datasets with which to perform the analyses (Islam, 2003). On the other hand, the emergence over the past decade of the socalled "New Economic Geography", initiated by Paul Krugman (1991a,b), has inspired fresh developments to help understand the uneven distribution across space of the economic activities at different levels of aggregation (Davis and Weinstein, 2002).,3 These two branches of research - the spatial agglomeration of economic activities and economic growth - are processes that are difficult to separate. In fact, there is evidence of a positive correlation between growth and geographical agglomeration of economic activities in relation to the Industrial Revolution in Europe (Baldwin and Martin, 2004). Furthermore, Quah (1996) suggested that the two countries that have achieved a high rate of growth and converged in per capita income terms toward the rest of Europe have also experienced the most marked regional divergence. Despite the important policy implications of regional divergence, there is little empirical evidence on spatial inequality and regional growth within countries, which is still an open question to be investigated.

Agglomeration or the clustering of economic activities occurs at many geographical levels in a number of different ways. In some fast-growing countries like China, Mexico, Russia, India and South Africa as well as most other developing and transition economies, there is a tendency for economic activities to be located on the coast and border regions (Kanbur and Venables, 2005). The case of the Chinese economy is probably one of the most fascinating ones and it is the focus of our work in this paper. China has transformed its economy from being centrally planned to one that is far more market-oriented. Economic reforms were focused on openness to trade and foreign investment, along with a set of policies aimed at liberalizing the economy. The creation of the so-called Special Economic Zones (SEZ) might explain the current imbalances across regions in China. Often located on the coast, the regions considered to be SEZ could attract investment from abroad, intensify their export activity, and eventually encourage economic activity. The Chinese government expected the development of these preferential zones to have influenced other inland regions through spillovers and externalities; however, such expectations have not

2 See Ottaviano and Puga (1998), Fujita et al. (1999), Fujita and Thisse (2002), Duranton and Puga (2004), Fujita and Krugman (2004), Ottaviano and Thisse (2004), Henderson (2005), Fujita (2005), Fujita and Mori (2005), and Fujita and Thisse (2005) for a survey of the literature on economic geography.

${ }^{3}$ Krugman (1991b) showed that the interaction of labor migration across regions with increasing returns and trade costs creates a tendency for firms and workers to cluster together as regions integrate. In addition, Venables (1996) addressed this issue by showing that vertical linkages between upstream and downstream industries, when both of them are imperfectly competitive, can play a role equivalent to that of labor migration in endogenously determining the size of the market in different regions. Linking this with new growth theory, Baldwin (1997) showed that factor accumulation can also sustain agglomerations, while Martin and Ottaviano (1996) looked at the inter-temporal component of input-output linkages. 
been fully accomplished even with the implementation of several economic packages specifically aimed at developing inland regions. ${ }^{4}$ In consequence, there are large differences between coastal and inland provinces, which have become more pronounced over time. For example, if one considers the distribution of labor productivity in 1952, it is observed that eastern provinces represented 48 percent of the total, while the western ones accounted for 19.5 percent. These figures rose to 65 percent and 14.19 percent respectively in 2008. Similar patterns are observed in capital intensity. By 1952, 37.73 percent of the total capital intensity belonged to the eastern regions, while 33.49 percent corresponded to the western ones. The difference became larger in 2008, when these percentages rose to 61.83 and 19.30 percent for eastern and western regions respectively. These figures reflect the agglomeration of the economic activities in the most developed areas of China, which benefited from a better location and preferential policies that speed up their rate of development. Another feature of this clustering phenomenon is reflected in the urban population. In 1995, the majority of cities in China had populations of less than a million inhabitants, while by 2008 there were 13 cities with more than 4 million inhabitants, 28 cities with between 2 and 4 million, and 81 cities with populations between 1 and 2 million. This uneven distribution of economic resources and population raises important questions from both the academic and the policymaking points of view. Are Chinese regions converging or diverging? If they are diverging, as was found in Pedroni and Yao (2006), might this result be misleading due to the fact that convergence occurs within small clusters? If clusters are relevant in the analysis, what provinces clustered and what drives convergence to a specific cluster? Understanding these questions is important to achieve regional convergence and constitutes the goal of this paper. Establishing key policy objectives for the clusters may improve the regional integration of the Chinese provinces, and therefore the economic development of the whole nation.

As mentioned in the most up-to-date survey on convergence carried out by Islam (2003), there are different notions of convergence that are linked with different methodological approaches. Since the initial Barro-regressions in either cross-section or panel data methods, a large body of empirical research has grown on this issue. Danni Quah's criticism of the results obtained using parametric techniques also inspired many works based on the dynamics of the distribution approach. Carlino and Mills (1993), Bernad and Durlauf (1995), and Oxley and Greasley (1995) developed the notion of stochastic convergence, which is based on time series analysis through the application of unit root tests. In this paper we combine both Quah's proposal and the stochastic convergence approach, i.e., we consider both the economic geography of the Chinese regions and the heterogeneity across them in order to test whether certain regions converge to a cluster-specific steady-state position.

Empirical evidence on stochastic regional convergence in the case of the Chinese economy is limited in the literature. ${ }^{5}$ To the best of our knowledge, there are only four papers on this issue, namely, Zhang et al. (2001), Smyth and Inder (2004), Ho and Li (2008),

\footnotetext{
${ }^{4}$ See Herrerias et al. (2011).

${ }^{5}$ However, there is a large body of empirical research using other notions of convergence such as $\beta$ - or $\sigma$-convergence, like Rozelle (1994), Jian et al. (1996), Chen and Fleisher (1996), Raiser (1998), Yao and Zhang (2001a, 2001b), Weeks and Yao (2003), Wang (2004), and Pedroni and Yao (2006), among others. On the other hand, only three papers were found that focused on the dynamics of the distribution of per capita income, namely, Bhalla et al. (2003), Sakamoto and Islam (2008), and Herrerías et al. (2011).
} 
and Keung and Lau (2010). ${ }^{6}$ The first paper, Zhang et al. (2001), investigated China's regional per capita income convergence over the period 1952-1997 using the Augmented Dickey Fuller (ADF, hereinafter) and Perron (Perron test, hereinafter) unit root tests. Their results, based on three aggregated regions in China (the eastern, central and western areas), report some evidence that both the eastern and western regions have converged to their own specific steady states over the last 40 years. On the other hand, Smyth and Indar (2004) performed two sets of unit root tests - with and without structural breaks - and then they compared the results for 25 provinces over the period 1952-1998. These authors use a wide range of unit root tests. Specifically, they employ the ADF test, the Phillips-Perron Test and the Elliot, Rothenberg and Stock Test, which do not take into account the existence of structural changes; the Perron test, which considers a single exogenous change, and finally they use the Zivot and Andrews and Lumsdaine and Papell Tests, which allow one and two endogenous structural changes, respectively. Their results indicate that when they allow for multiple structural breaks in the individual ADF tests, the evidence is mixed. When both breaks in the trend function are restricted to the intercept, there is no additional evidence against divergence. If, however, they allow for two breaks in both the intercept and the slope of the trend function, the authors find convergence for less than half of the provinces at the 5 percent significance level. In addition, Ho and Li (2008) employed similar tests to those used by the previous authors for four inequality measures. This analysis was conducted at national level, but the inequality measures were obtained from provincial data from 1952 to 2000 . The authors found that the regional inequality measures are trend stationary with structural breaks and argued that if no measures are taken to deal with this unfavorable trend, regional inequality will continue to increase in the future. Finally, Keung and Lau (2010) investigated income convergence across the Chinese regions by applying nonlinear panel unit root test, specifically, the Exponential Smooth AutoRegressive Augmented Dickey-Fuller (ESTAR-ADF) unit root test developed by Cerrato et al. (2008) for the period 1952-2003. Their results indicate that regional inequalities have increased since the reforms began.

This paper focuses on the convergence behavior and regional growth across Chinese regions, but it differs from previous works in many significant aspects. Firstly, unlike previous papers that only examined per capita income, we also analyze the convergence behavior of labor productivity, capital intensity and total factor productivity, which provides richer information about the convergence process and regional growth (Kaldor, 1960; 1961). In addition, while per capita GDP is relevant for the welfare of the population, much of the growth theory focuses on the productivity capacity of regions. The data map the theory more easily when we look at output per worker (Acemoglu, 2009). Secondly, we use the new panel unit root approach suggested by Phillips and Sul (2007). This panel convergence test takes into account the fact that regions experience transitional dynamics but without imposing homogeneous technological progress - an assumption that is extensively used in growth studies. As noted by these authors, under technological heterogeneity, the analysis of convergence by the standard panel stationarity test is not valid. This methodology, proposed by Phillips and Sul (2007), is based on a general form of a nonlinear time-varying factor model. The notion of convergence implied in this methodology is analogous to sigma convergence. In contrast to other methodologies commonly used in the literature, the Phillips and Sul (2007) methodology is especially appealing for the case of China, which is a large economy in transition. Finally, we use the

\footnotetext{
${ }^{6}$ It is also possible to find evidence using this notion of convergence in Ma et al. (2009) and Ma and Oxley (2010), which investigated energy price convergence in the case of China.
} 
most recent data available in the case of Chinese provinces, which cover the period from 1952 to 2008.

Our results indicate that Chinese regions have converged into clubs. However, it is observed that Heilongjiang is diverging in terms of labor productivity and capital intensity, while Liaoning and Guizhou display a similar pattern only in terms of labor productivity, and Shanxi and Hebei in terms of capital intensity. These results indicate that specific economic packages need to be implemented in the identified clusters, with special attention to those regions that show a divergence behavior, in order to guarantee the sustainability and equality of regional growth.

The structure of the paper is as follows. In section 2 we describe the data used in this work. The technical issues are explained in section 3. In section 4 we report the results, and conclusions are discussed in section 5 .

\section{Data}

The data used in this paper consist in four macroeconomic variables that allow us to investigate the convergence behavior of the Chinese regions in terms of both welfare and regional growth. Specifically, we consider per capita income (GDP/N), output per worker $(G D P / L)$, capital intensity $(K / L)$ and total factor productivity $(T F P)$. We analyze this issue for 28 Chinese regions from 1952 to 2008, which is the most recent annual data available from the National Bureau of Statistics of China. ${ }^{7,8}$ We compute TFP from the traditional Solow model following the Cobb-Douglas production function with constant returns to scale, which can be expressed as follows: $Y=A K^{\alpha} L^{1-\alpha}$. By taking the natural logarithm and differentiating over time, one arrives at the following expression: ${ }^{9}$

$$
\dot{g}=\dot{a}+\alpha \cdot \dot{k}
$$

where $g$ is the growth rate of labor productivity, $a$ is the growth rate of technological progress, $k$ is the growth rate of the capital-labor ratio, and $\alpha$ the share of capital in growth. In our case, the coefficient of interest for the TFP estimates is the last one, $\alpha$. We split the sample into the pre- and post-reform periods (1952-1978 and 1979-2008) and estimate $\alpha$ by

\footnotetext{
7 They are expressed in real terms, based on the regional GDP deflator. The base year is $1953=$ 100. In addition, for the sake of simplicity, we use the concept of provinces throughout this paper. However, in China there are 23 provinces, 5 autonomous regions, 4 municipalities, and 2 special administration regions (SAR). We have excluded Hainan and Tibet due to the lack of data. In addition, this paper focuses on mainland China, and consequently we have also excluded Taiwan, Hong Kong and Macao. Chongqing is included in Sichuan province, since it was part of it until 1997. This is standard practice in Chinese studies. In relation to this, there is much debate as to the quality of the Chinese statistics. However, Holz (2005), Chow (2006) and Bai et al. (2006) present quality Chinese statistics for examining long-run trends. We used data from China Compendium of Statistics 1949-2008 edited by the National Bureau of Statistics of China (NBS) in 2010, which provided us with information that was homogeneous enough, both across Chinese provinces and over time, to conduct this study properly. We would like to thank Yanrui $\mathrm{Wu}$ for the data on capital stock; for further details in his work, see Wu (2008).

8 There is a large body of research that has covered the pre- and post-reform periods in Chinese studies, using unit root test and cointegration techniques. See, for instance, Chow (1987), Li (2000), Zhang et al. (2001), Smyth and Inder (2004), Matsuki and Usami (2007), Herrerias and Orts (2010), Keung and Lau (2010), Ma et al. (2009) and Ma and Oxley (2010), among others.

${ }_{9}^{9}$ We have omitted the subscripts for the sake of simplicity.
} 
using panel data methods allowing for the heterogeneity of Chinese regions. ${ }^{10}$ According to our estimations, $\alpha$ takes a value of 0.4 in the pre-reform period and 0.6 afterwards.

Figure 1 shows the box plots of labor productivity, capital intensity, total factor productivity, and per capita income in 1952, 1978 and 2008 as a practical way of summarizing the characteristics of the data. The box plot is a useful tool to analyze the dynamics of changes in a distribution's characteristics such as the existence, appearance or disappearance of outliers, the dispersion or concentration of the data, and the symmetry or asymmetry of a distribution. The vertical axis represents the scale of the variable. The box represents the interquartile range, a common measure of dispersion, and contains 50 percent of the probability mass of the distribution. A small interquartile range is shown by a relatively short box, and indicates a tighter concentration of the variable's mid-values. The median is reported on the horizontal line, which provides information about the symmetry of the distribution. The circles outside the box, as in the case of per capita income in 1978, are outliers. If there are no outliers, the extreme values indicate the maximum and minimum of the dataset.

\footnotetext{
${ }^{10}$ We do not report these results to save space in the paper, but they are available from the authors upon request. The aim of this paper is not to obtain the precise estimates of TFP or to partake in the debate on TFP measurement. Our objective is simpler and consists mainly in obtaining an approximation of the contribution of capital to the growth rate in order to reach TFP and perform analyses with the other variables considered in this study. See Herrerias and Orts (2010) for a similar application of the measurement of TFP.
} 
Figure 1: Box Plots, labor productivity, capital intensity, per capita income, and TFP, 1952, 1978 and 2008

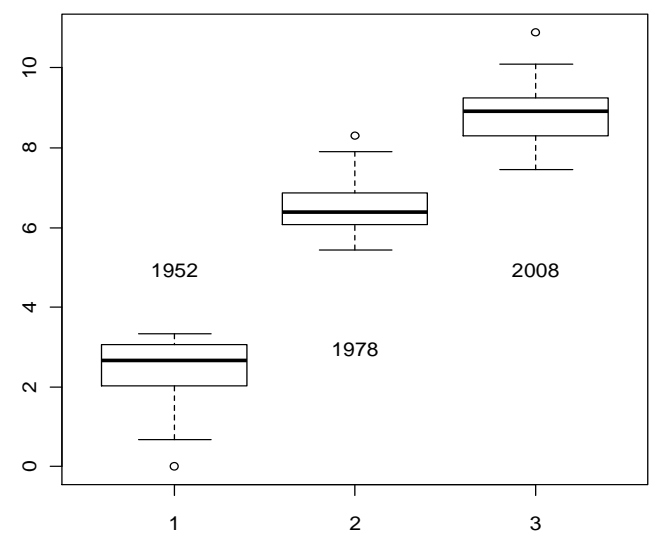

(a) Labor Productivity

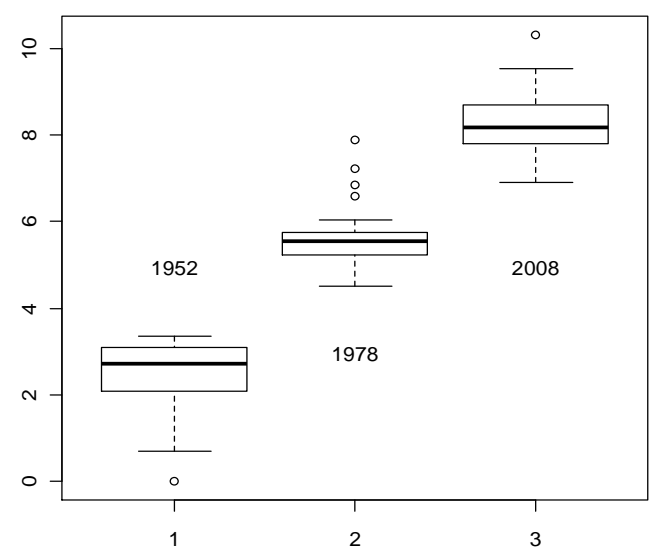

(b) Per Capita Income

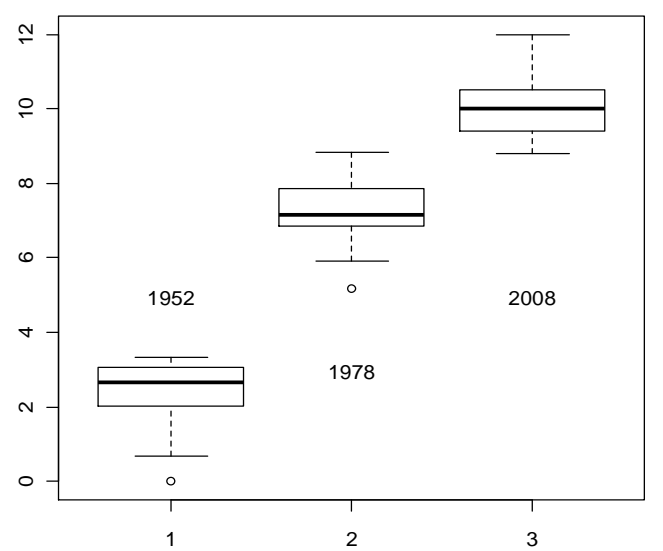

(c) Capital Intensity

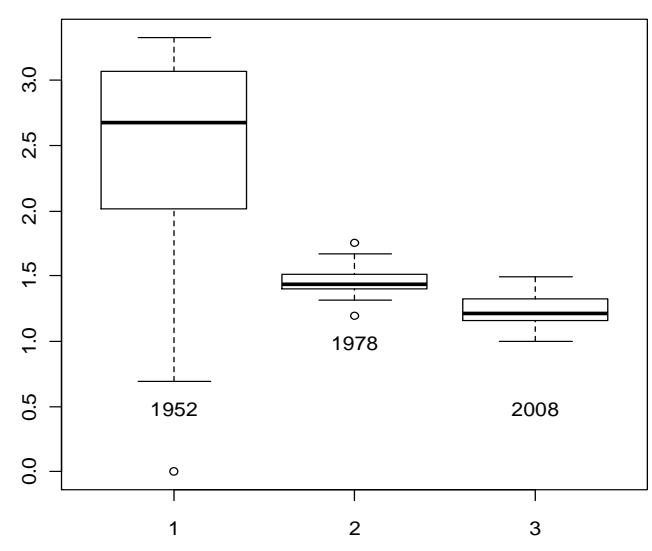

(d) Total Factor Productivity

Figure 2 shows a series of maps of the Chinese regions indicating the geographical distribution of per capita income, labor productivity, capital intensity, and total factor productivity in 1952 and 2008. 
Figure 2: Per capita income, labor productivity, capital intensity, and TFP in 1952 and 2008

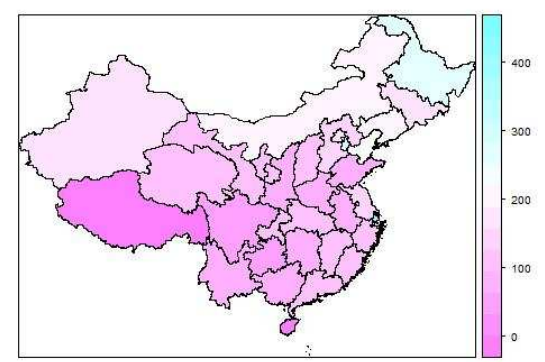

(a) Per Capita Income in 1952

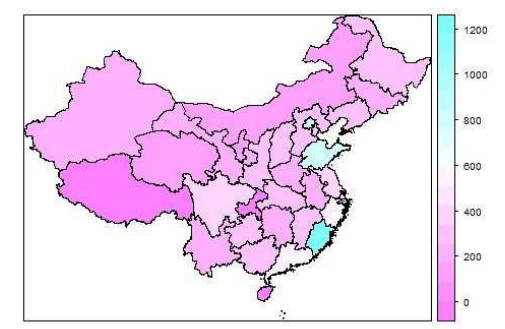

(c) Labor Productivity in 1952

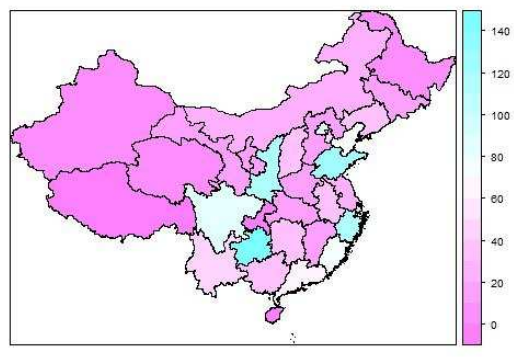

(e) Capital Intensity in 1952

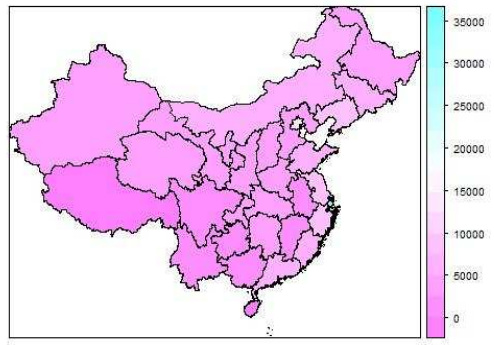

(b) Per Capita Income in 2008

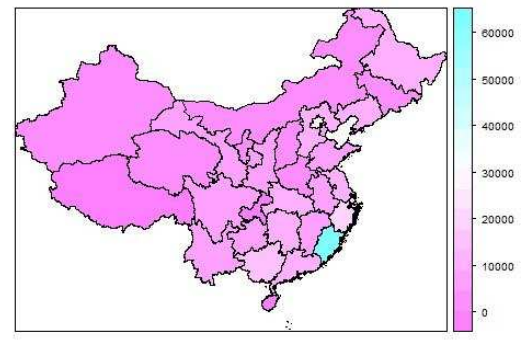

(d) Labor Productivity in 2008

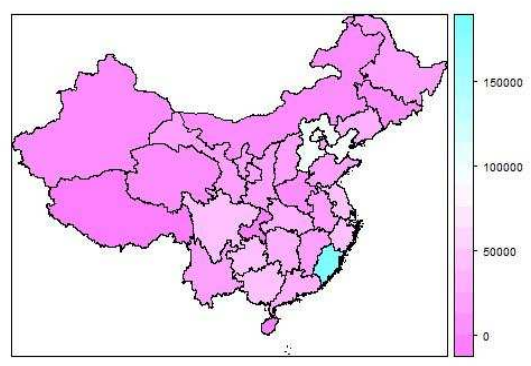

(f) Capital Intensity in 2008 


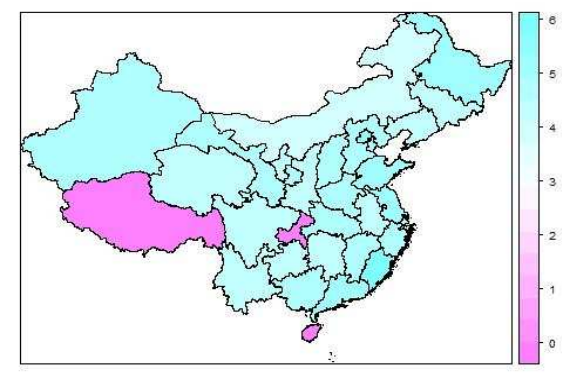

(g) Total Factor Productivity in 1952

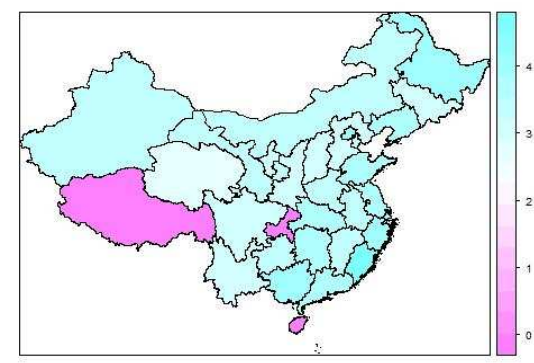

(h) Total Factor Productivity in 2008

\section{Methodology}

\section{a. A background on Unit Root Tests}

Traditionally, the ADF and PP unit root tests are commonly used in the empirical papers on convergence. However, it is well known that they suffer from different shortcomings and the consequence is over-rejection of the unit-root hypothesis. ${ }^{11} \mathrm{Ng}$ and Perron (2001) developed a unit root test (M-test) to overcome the lower power of these traditional tests due to size distortions, as well as to provide a more adequate selection of lag length. The test is based on GLS detrending in order to achieve substantial power gains, which allow a more precise autoregressive spectral density estimator, provided that the truncation lag is selected appropriately. ${ }^{12}$ However, in this first generation of unit root tests, the presence of structural breaks in the data generating process is ignored. The second generation of unit root tests deals with this issue by considering a single exogenous break, as developed by Pierre Perron. This test has also been criticized in the literature on the grounds that it may provide weak results, since it only considers one structural break. A similar argument can be applied to Zivot and Andrews' test, since they only considered a single endogenous structural break in their model (Cook, 2008): if those tests that do not consider structural breaks are weak, the same argument is feasible for tests that consider only a structural break if in the data generating process there are more than one. In this regard, Lee and Strazicich (2003) developed a unit root test that allows for the presence of one or two endogenous structural breaks and displays better properties than the previous ones. On the other hand, all the aforementioned tests assume a linear form. In the presence of stationary nonlinear processes, linear unit root tests might report misleading results since they fail to reject the null of unit root (Enders and Granger, 1998). To overcome this problem Kapetanios et al. (2003) proposed a unit root test against the null of nonlinear

\footnotetext{
11 These tests suffer from low power when the root of the autoregressive polynomial is close to but less than unity and from severe size distortions when the moving-average polynomial of the first differenced series has a large negative root. See Ng and Perron (2001), pp. 1519-1520.

${ }_{12}$ Perron and Ng (1996) showed that the M tests have dramatically smaller distortions than most (if not all) unit-root tests in the literature in the cases of negative moving-average errors if the autoregressive spectral density estimators defined above are used in conjunction with a suitably chosen $\mathrm{k}$.
} 
stationary. However, the time series approach cannot deal with individual heterogeneity and so a panel approach is preferred.

As we stated before, panel data techniques have attracted a significant amount of interest among economists owing to their ability to model the heterogeneity of individuals empirically. One popular empirical model involves a common factor structure and idiosyncratic effects. These works have recently been extended in several directions, such as in the determination of the number of common factors and for inference in panel models with nonstationary common factors and idiosyncratic errors (Bai, 2003 and 2004; Bai and $\mathrm{Ng}, 2002$ and 2006). However, none of these tests allow regional clusters to be tested for, like the one applied in this paper developed by Phillips and Sul (2007).

\section{b. The relevance of regional clusters: Phillips and Sul $\log t$ test}

As we mentioned earlier, econometricians have made a significant effort to develop new unit root tests that have been applied to empirical studies in many fields in economics. Initially, they were used in time series analyses and are currently also applied to panel data, since the availability of new and richer datasets allow this latter approach to be carried out. The advantage of supporting the analysis with panel data techniques compared with the time series approach is that researchers can make more realistic models by taking into account the heterogeneity of individuals. In the case of the Chinese economy this feature is particularly relevant since both the economic size and population of each region are larger than any European country and there are also notable differences across provinces. Moreover, different economic policies introduced by the Chinese government benefit some provinces, often located on the coast, at the expense of other inland regions. This seems to suggest that regional clusters are important in regional economic development and the convergence process. In contrast to previous unit root tests used in the analysis of regional convergence in China, the log $t$ proposed by Phillips and Sul (2007) takes these two aspects into account. In addition, the test presents a nonlinear time-varying form that enables us to consider the significant transformation of the Chinese economy in the last four decades. Finally, the test considers different transition paths that fit an economy in transition, such as China, much better.

The starting point of the test is a simple factor model as in (1), where Phillips and Sul (2007) introduced two modifications in comparison with previous literature:

$$
X_{i t}=\delta_{i} \mu_{t}+\epsilon_{i t}
$$

where $\delta_{i}$ measures the idiosyncratic distance between some common factor $\mu_{t}$ and the systematic part of $X_{i t}$. This model seeks to capture the evolution on the individual $X_{i t}$ in relation to $\mu_{t}$ by means of its two idiosyncratic elements, that is, the systematic element $\delta_{i}$ and the error $\epsilon_{i t}$. Phillips and Sul (2007) modified this initial model by allowing the systematic idiosyncratic element to evolve over time, thereby accommodating heterogeneous agent behavior and evolution within that behavior by means of a timevarying factor-loading coefficient $\delta_{i t}$. Furthermore, they allow $\delta_{i t}$ to have a random component, which absorbs $\epsilon_{i t}$ in (1) and allows for possible convergence behavior in $\delta_{i t}$ over time in relation to the common factor $\mu_{\mathrm{s}}$.

Thus, Phillips and Sul's model with time-varying representation takes the following expression:

$$
X_{i t}=\delta_{i t} \mu_{t}
$$


The time-varying behavior of $\delta_{i t}$ is modeled in a semi-parametric form as follows:

$$
\delta_{i t}=\delta_{i}+\sigma_{i} \varepsilon_{i t} L(t)^{-1} t^{-a}
$$

where $\delta_{i t}$ is fixed, $\varepsilon_{i t}$ is i.i.d $(0,1)$ across $i$ but weakly dependent on $t$, and $\mathrm{L}(t)$ is a slowly varying function (like $\log t$ ) for which $\mathrm{L}(t)$ tends to infinity and $t$ also goes to infinity. This formulation ensures convergence of the parameter of interest for all $\alpha \geq 0$, which is the null hypothesis of interest. ${ }^{13}$

The second contribution of these authors lies in the development of a test of convergence that does not rely on any particular assumption concerning trend stationarity or stochastic nonstationarity in $X_{i t}$ or $\mu_{t}$. In addition, the nonlinear form used by these authors is sufficiently general to include a wide range of possibilities in terms of time paths for $\delta_{i t}$ and their heterogeneity over $i$ along with the possibility that the individual behavior may also be transitionally divergent.

Then, the null hypothesis of convergence is set as:

$$
H_{0}=\delta_{i}=\delta \text { and } \alpha \geq 0
$$

Against the alternative:

$$
H_{1}=\delta_{i} \neq \delta \text { for all } \text { or } a<0
$$

The test is made up of three stages (Phillips and Sul, 2007, p.1788). In the first step, the cross-sectional variance ratio is constructed, and then in the second step the conventional robust $t$ statistic, $t_{b}$, is computed for the estimated coefficient. Finally, in the third step, an autocorrelation and heteroskedasticity robust one-side $t$ test of the inequality null hypothesis $\alpha \geq 0$ is applied using the estimated coefficient and HAC standard errors. At the 5 percent level, the null hypothesis of convergence is rejected if the statistic has a value below -1.65 .

However, the novel aspect of this approach is that convergence patterns within groups can be examined using $\log t$ regressions, that is, the existence of club convergence and then clustering. This fact is particularly relevant since the rejection of the null of convergence does not necessarily imply divergence, since different scenarios can be met, such as separate points of equilibrium or steady-state growth paths, as well as convergence clusters and divergent regions in the full panel. The existence of club convergence raises an important concern, that is, how to identify the regions that belong to each cluster. In this regard, Phillip and Sul (2007) suggested the following method.

In the first step, individuals in the panel must be ordered according to the last observation in the panel. In the second step, the so-called "core group", Gk, should be identified by selecting the first $k$ highest individuals in the panel to form the subgroup $G_{k}$ for some $\mathrm{N}>\mathrm{k} 22$, and then the $\log t$ regression is run and the convergence test statistic $t_{k}\left(G_{k}\right)$ is obtained for this subgroup. Then, the core group size $k^{*}$ is chosen by maximizing $t_{k}$ over $k$ according to the criterion:

$$
k^{*}=\operatorname{argmax}\left\{t_{k}\right], \text { subject to } \min \left\{t_{\mathrm{h}}\right\}>-1.65
$$

\footnotetext{
${ }^{13}$ See additional technical details in Phillips and Sul (2007).
} 
The latter condition ensures that the null hypothesis of convergence is supported for each $k$. The rule for classifying the groups of regions into clubs is straightforward. For example, if all the regions belong to the same group, then the size of the club will be N. In contrast, if there are regions that do not belong to that group, the clusters will have a size lower than N. More formally, this implies that if the condition $m m\left[t_{k}\right]>-1.65$ is not held for $k=2$, then the highest individual in $\mathrm{G}_{\mathrm{k}}$ can be dropped from each subgroup and new subgroups are created. This process is repeated as many times as necessary until the condition is satisfied. If at the end of this process there are subgroups that have been created (said to be club convergent), but there are others that do not satisfy the condition, then it is said that those individuals diverge.

\section{Results}

Results on club convergence for per capita income are presented in Table 1, while the cases of labor productivity, capital intensity, and total factor productivity are reported in Tables 2-4 respectively.

\section{a) Per Capita Income}

Figure 3 shows a map of the results based on per capita income, where the club convergence across Chinese regions from 1952 to 2008 can be observed.

Figure 3: Map of club convergence across Chinese regions, per capita income

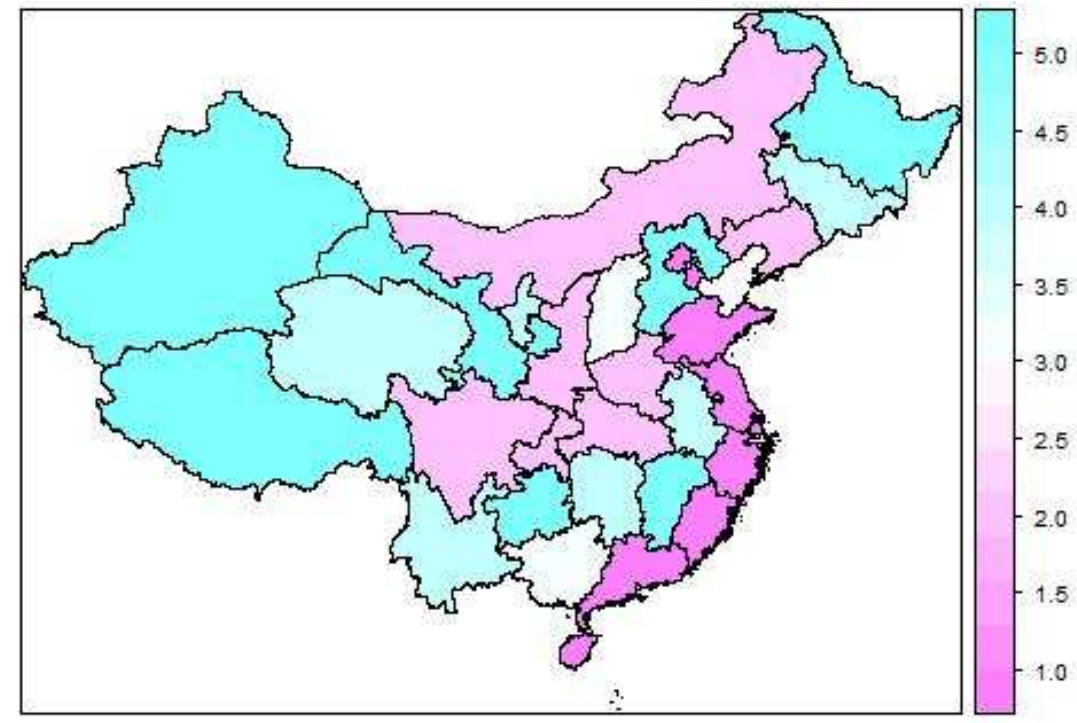


Note: 1 means club 1; 2, club 2; 3, club 3; 4, club 4 and 5, club 5. See Table 1 below.

Table 1 reports the results on per capita income, where five convergent clubs were found. Some of the most developed regions such as Shanghai, Beijing, Tianjin, Zhejiang, Guangdong, Shandong and Fujian appear in the first cluster. The second convergent club includes regions like Liaoning, Hubei, Henan, Inner Mongolia, Shaanxi, Sichuan and Chongqing. Only Guangxi and Shanxi belong to the third one. The fourth one is made up of Jilin, Anhui, Qinghai, Ningxia and Yunnan, while regions like Heilongjiang, Jiangxi, Hebei, Xinjiang, Gansu and Guizhou are in the last group.

As we can observe from our results, the regions that display the highest levels of per capita income are located along the coast. These regions have enjoyed exceptional communications and benefited from preferential policies set by the Chinese government. An export-oriented strategy along with the significant foreign inflows and a relatively lower presence of the state sector are factors that account for that agglomeration in this area of China. 
Table 1: Convergence Test, per capita income

\begin{tabular}{|c|c|c|c|}
\hline & \multicolumn{2}{|c|}{ Sub Club Convergence } & \multirow[t]{2}{*}{ Regions } \\
\hline & $\boldsymbol{\beta}$ & t-stat. & \\
\hline const & -1.363 & -10.144 & \multirow{2}{*}{$\begin{array}{l}\text { Shanghai, Beijing, Tianjin, Jiangsu, } \\
\text { Zhejiang, Guangdong, Shandong Fujian }\end{array}$} \\
\hline $\log t$ & 0.236 & 4.268 & \\
\hline \multicolumn{4}{|c|}{ Check whether the rest of the group forms the other convergent club: } \\
\hline & $\boldsymbol{\beta}$ & t-stat. & \\
\hline const & 0.369 & 35.466 & \multirow{2}{*}{ Since $t$-stat $<-1.65$, repeat clustering procedures } \\
\hline $\log t$ & -0.830 & -193.720 & \\
\hline \multicolumn{4}{|c|}{ 2nd Convergent Club test } \\
\hline & $\boldsymbol{\beta}$ & t-stat. & \\
\hline const & -1.821 & -9.625 & \multirow{2}{*}{$\begin{array}{l}\text { Liaoning, Hubei, Henan, } \\
\text { Inner Mongolia, Shaanxi, Sichuan, Chongqing }\end{array}$} \\
\hline $\log t$ & 0.438 & 5.625 & \\
\hline \multicolumn{4}{|c|}{ Check whether the rest of the group forms the other convergent club: } \\
\hline & $\boldsymbol{\beta}$ & t-stat. & \\
\hline const & 0.152 & 8.185 & \multirow{2}{*}{ Since $t$-stat $<-1.65$, repeat clustering procedures } \\
\hline $\log t$ & -0.678 & -88.746 & \\
\hline \multicolumn{4}{|c|}{ 3rd Convergent Club test } \\
\hline & $\boldsymbol{\beta}$ & t-stat. & \\
\hline const & -5.583 & -9.986 & Guangxi and Shanxi \\
\hline $\log t$ & 1.300 & 5.650 & \\
\hline \multicolumn{4}{|c|}{ Check whether the rest of the group forms the other convergent club: } \\
\hline & $\boldsymbol{\beta}$ & t-stat. & \\
\hline const & 0.174 & -5.148 & \multirow{2}{*}{ Since $t$-stat $<-1.65$, repeat clustering procedures } \\
\hline $\log t$ & 0.467 & -33.482 & \\
\hline \multicolumn{4}{|c|}{ 4th Convergent Club test } \\
\hline & $\boldsymbol{\beta}$ & t-stat. & \\
\hline const & -1.051 & -17.010 & Jilin, Hunan, \\
\hline $\log t$ & 0.146 & 5.744 & Anhu1, Qingha1, Ningxia, Yunnan \\
\hline \multicolumn{4}{|c|}{ Check whether the rest of the group forms the other convergent club: } \\
\hline & $\boldsymbol{\beta}$ & t-stat. & \\
\hline const & -1.521 & -8.710 & \multirow{2}{*}{ Since $t$-stat $>-1.65$, the rest forms a convergent club } \\
\hline $\log t$ & 0.183 & 2.552 & \\
\hline
\end{tabular}

Heilongjiang, Jiangxi, Hebei, Xingjiang, Gansu and Guizhou 
The second group is quite different from the previous one, since they are not provinces that are characterized by significant levels of foreign trade and investment. Instead, they are regions that are relevant for the Chinese economy due to their natural resources, such as the case of Inner Mongolia, where the highest coal output is obtained, and Sichuan and its neighbors because of the production of electricity. In general, the regions that belong to this group are the ones where economic reforms started later as compared with the previous group, and therefore they grow at different speeds, creating their own cluster. Moreover, in this zone the rural population predominates, with a moderate presence of the state sector, which has in turn conditioned their economic structure and development.

The remaining provinces are plausible examples of the effect of implementing the reforms later, as in the case of Guangxi and Hunan, which attempted to catch up with Guangdong. This may also be a consequence of their unfortunate economic geography, as in the case of the western regions, where there are few economic incentives to encourage economic activity by the non-state sector. Although several economic packages were designed to promote the growth of these regions, according to our results, they have not converged with the rest of the provinces but to their own cluster.

\section{b) Labor Productivity}

Figure 4 shows a map of the results based on labor productivity, where there are three convergent clubs along with three regions that exhibit a divergent path from 1952 to 2008.

Figure 4: Map of club convergence across Chinese regions, labor productivity

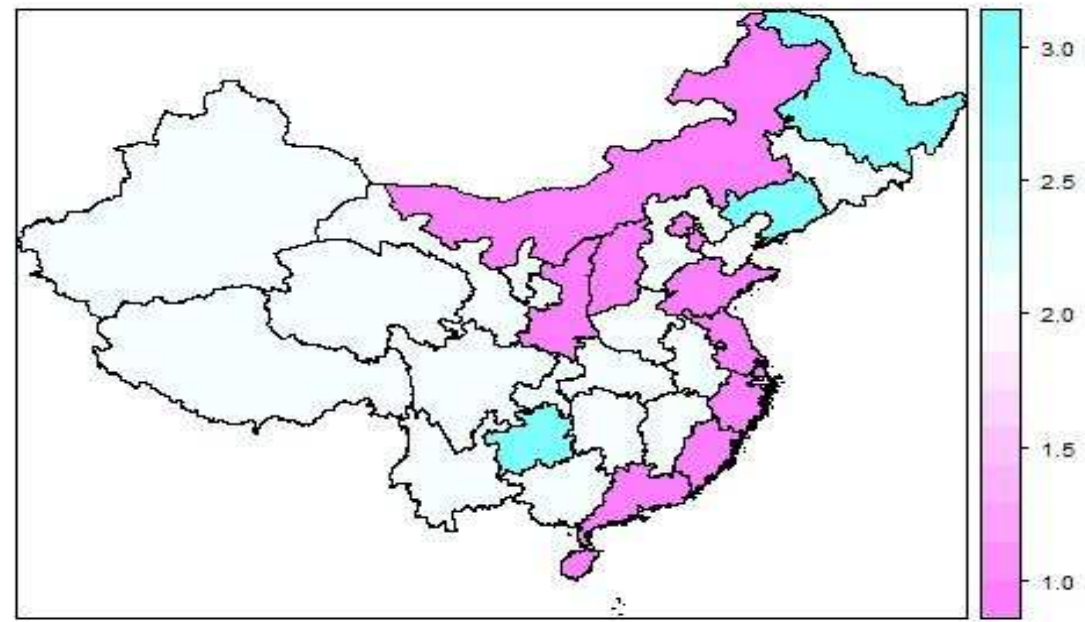

Note: 1 means club 1; 2, club 2 and 3, a divergent club.

See Table 2 below.

Table 2. Convergence test, Labor Productivity

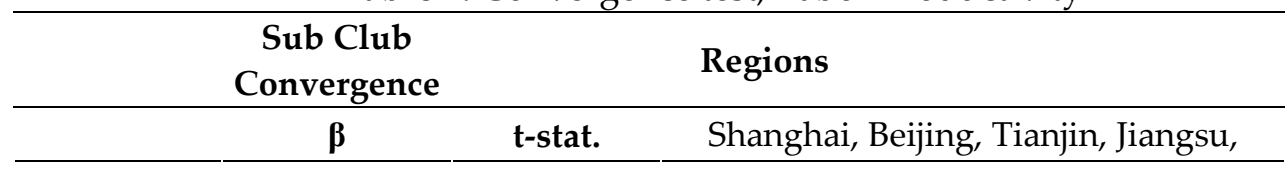




\begin{tabular}{|c|c|c|c|}
\hline const & -1.518 & $\begin{array}{r}-10.334 \\
2.562\end{array}$ & $\begin{array}{l}\text { Zhejiang, Guangdong, Shandong, } \\
\text { Fujian, Shanxi, Inner Mongolia, } \\
\text { Shaanxi }\end{array}$ \\
\hline \multicolumn{4}{|c|}{ Check whether the rest of the group forms the other convergent club: } \\
\hline & $\boldsymbol{\beta}$ & t-stat. & \\
\hline const & -0.132 & -4.000 & Since $t$-stat $<-1.65$, repeat clustering \\
\hline $\log t$ & -0.523 & -38.604 & procedures \\
\hline \multicolumn{4}{|c|}{ 2nd Convergent Club test } \\
\hline & $\boldsymbol{\beta}$ & t-stat. & \\
\hline const & -0.089 & $\begin{array}{c}-11.214 \\
-2.917\end{array}$ & $\begin{array}{c}\text { Guangxi, Jilin, Hubei, Hunan, Anhui, } \\
\text { Jiangxi, Henan, Hebei, Xingjiang, } \\
\text { Qinghai, Ningxia, Gansu, Yunnan, } \\
\text { Sichuan }\end{array}$ \\
\hline \multicolumn{4}{|c|}{ Check whether the rest of the group forms the other convergent club: } \\
\hline & $\boldsymbol{\beta}$ & t-stat. & \\
\hline const & 0.300 & 10.761 & Since $t$-stat $<-1.65$, repeat clustering \\
\hline $\log t$ & -0.876 & -76.491 & procedures \\
\hline \multicolumn{4}{|c|}{ 1st Divergent Club } \\
\hline \multicolumn{4}{|c|}{ Heilongjiang, Liaoning and Guizhou } \\
\hline
\end{tabular}

Table 2 shows the results based on labor productivity, in which we found two convergent clubs and three provinces that diverge. Our results suggest that regions like Shanghai, Beijing, Tianjin, Jiangsu, Zhejiang, Guangdong, Shandong, Fujian, Shanxi, Inner Mongolia and Shaanxi belong to the first convergence club, while provinces like Guangxi, Jilin, Hubei, Hunan, Anhui, Jiangxi, Henan, Hebei, Xinjiang, Qinghai, Ningxia, Gansu, Yunnan and Sichuan belong to the second convergent club. In contrast, Heilongjiang, Liaoning and Guizhou display a divergence behavior.

Labor productivity across Chinese regions presents a performance that is quite different from per capita income, since in the latter we found five small clusters, and now it is only possible to see two convergence clubs and one set of regions that are diverging. Here, it is clearer where the economic activity is located, that is, in the eastern part of China and the North-West. As we mentioned above, the better geographical location on the coast, with the proximity to Hong Kong and Japan benefited trade activities. Furthermore, the two main coal-producing regions in China are in the North-West, and in addition to the aforementioned Inner Mongolia, another producer is Shanxi. The coal from these areas is used in the industrial sector, which accounts for more than 70 percent of all the coal used and it is the main source of energy. On the other hand, the other large convergent group includes the regions that are located in central and western regions which display a lower degree of development and dynamic performance. It seems that there is more convergence in terms of labor productivity than in terms of per capita income, since more regions belong to the latter and they show similar characteristics. However, here and contrary to the previous findings, we found that northern regions like Heilongjiang and Liaoning are diverging. These provinces are characterized by the predominance of heavy industry with the presence of SOE firms, often with high losses and difficulties when it comes to gaining access to funding. Similar behavior is found in the south in Guizhou, which supports active 
programs like Great Western Development program to encourage these regions.

Nonetheless, more economic policies focusing on the development of the productive infrastructure, innovation activities, human capital and openness are needed and may improve their current situation.

\section{c) Capital Intensity}

Figure 5 shows a map of the results based on capital intensity, where there are five convergent clubs and one that diverges in China's regions from 1952 to 2008.

Figure 5: Map of club convergence across Chinese regions, capital intensity

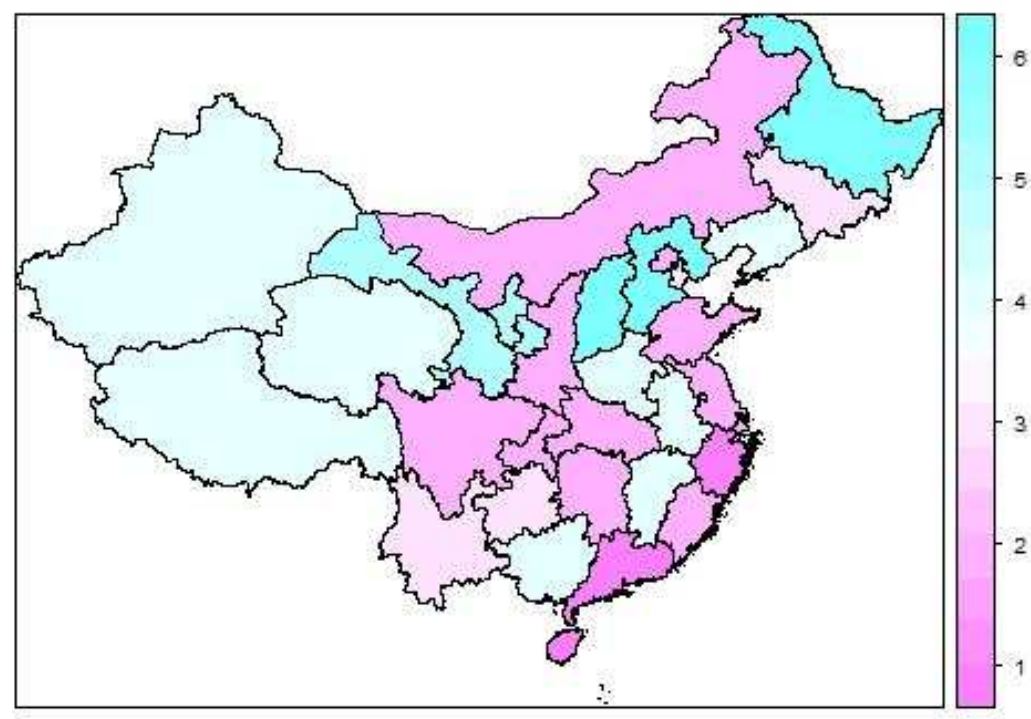

Note: 1 means club 1; 2, club 2; 3, club 3; 4, club 4; 5, club 5 and 6 , a divergent club. See table below.

Table 3: Convergence test, Capital intensity

\begin{tabular}{|c|c|c|c|}
\hline & $\begin{array}{c}\text { Sub Club } \\
\text { Convergence }\end{array}$ & & Regions \\
\hline & $\boldsymbol{\beta}$ & t-stat. & \\
\hline const & -4.589 & -7.408 & Zhejiang and Guangdong \\
\hline $\log t$ & 1.530 & 6.002 & \\
\hline \multicolumn{4}{|c|}{ Check whether the rest of the group forms the other convergent club: } \\
\hline & $\boldsymbol{\beta}$ & t-stat. & \\
\hline const & 0.188 & -2.226 & Since $t$-stat $<-1.65$, repeat clustering \\
\hline $\log t$ & -0.645 & -29.541 & procedures \\
\hline \multicolumn{4}{|c|}{ 2nd Convergent Club test } \\
\hline & $\beta$ & t-stat. & \\
\hline & & & Shanghai, Beijing, Jiangsu, Shandong, \\
\hline
\end{tabular}




\begin{tabular}{|c|c|c|c|}
\hline $\begin{array}{c}\text { const } \\
\log t\end{array}$ & $\begin{array}{c}-1.854 \\
0.299\end{array}$ & $\begin{array}{c}-9.642 \\
3.785\end{array}$ & $\begin{array}{l}\text { Fujian, Hubei, Hunan, Inner Mongolia, } \\
\text { Shaanxi, Sichuan }\end{array}$ \\
\hline \multicolumn{4}{|c|}{ Check whether the rest of the group forms the other convergent club: } \\
\hline & $\boldsymbol{\beta}$ & t-stat. & \\
\hline const & -0.113 & -2.116 & Since $t$-stat $<-1.65$, repeat clustering \\
\hline $\log t$ & 0.594 & -26.973 & procedures \\
\hline \multicolumn{4}{|c|}{ 3rd Convergent Club test } \\
\hline & $\boldsymbol{\beta}$ & t-stat. & \\
\hline const & -1.366 & -7.560 & Tianjin, Jilin, Yunnan, Guizhou \\
\hline $\log t$ & 0.133 & 1.787 & \\
\hline \multicolumn{4}{|c|}{ Check whether the rest of the group forms the other convergent club: } \\
\hline & $\boldsymbol{\beta}$ & t-stat. & \\
\hline const & 0.201 & 6.994 & Since $t$-stat $<-1.65$, repeat clustering \\
\hline $\log t$ & -0.782 & -66.145 & procedures \\
\hline \multicolumn{4}{|c|}{ 4th Convergent Club test } \\
\hline & $\boldsymbol{\beta}$ & t-stat. & \\
\hline const & -1.237 & -6.755 & $\begin{array}{l}\text { Liaoning, Guangxi, Anhui, Jiangxi, } \\
\text { Henan, Xinjiang, Qinghai }\end{array}$ \\
\hline \multicolumn{4}{|c|}{ Check if the rest group forms the other convergent club: } \\
\hline & $\boldsymbol{\beta}$ & t-stat. & \\
\hline const & 0.127 & 3.985 & Since $t$-stat $<-1.65$, repeat clustering \\
\hline $\log t$ & -0.742 & -56.623 & procedures \\
\hline \multicolumn{4}{|c|}{ 5th Convergent Club } \\
\hline & $\boldsymbol{\beta}$ & t-stat. & \\
\hline const & -1.804 & -9.258 & Ningxia and Gansu \\
\hline $\log t$ & 0.312 & 3.893 & \\
\hline
\end{tabular}

Check whether the rest of the group forms the other convergent club:

\begin{tabular}{cccc}
\hline & $\boldsymbol{\beta}$ & $\mathbf{t}$-stat. \\
\hline const & 0.509 & 35.383 & Since $t$-stat $<-1.65$, repeat clustering \\
$\log t$ & -0.932 & -157.605 & procedures \\
\hline \multicolumn{4}{c}{ 1st Divergent Club } \\
\hline
\end{tabular}

Heilongjiang, Shanxi, Hebei

Table 3 presents the results on capital intensity, where five convergent clubs and one that diverges were found. Only Zhejiang and Guangdong regions belong to the first group. The second one includes Shanghai, Beijing, Jiangsu, Shandong, Fujian, Hubei, Hunan, Inner Mongolia, Shaanxi, and Sichuan. Regions like Tianjin, Jilin, Yunnan and Guizhou are classified in the third one. The fourth group contains regions like Liaoning, Guangxi, 
Anhui, Jiangxi, Henan, Xinjiang, Qinghai, while only Ningxia and Gansu are in the fifth group. Heilongiiang, Shanxi and Hebei, however, are found to diverge.

These results, and especially those that correspond to the first two clusters, are quite similar to the previous ones, in the sense that concentration of capital intensity occurs only along the coast and in the northern regions. The difference depends on the group of regions that are clustering in small clubs, and growing at different speeds. While it seems that China's regions are split into two big groups in terms of labor productivity, in the case of capital intensity there are important differences. This behavior is similar to that found in the case of per capita income. However, now there are regions that diverge and economic policies should focus there.

\section{d) Total Factor Productivity}

The most relevant information about what drives the convergence and regional growth process is provided by the performance of the total factor productivity. We found that there are five small clusters in per capita income and capital intensity, but two main groups in labor productivity. Analyzing the role of TFP will provide useful insights for the development of regional policies. These results are shown in Table 4. We found a large club made up of the majority of regions like Shanghai, Beijing, Tianjin, Liaoning, Zhejiang, Shandong, Fujian, Guangxi, Heilongjiang, Shanxi, Anhui, Henan, Hebei, Inner Mongolia, Qinghai, Ningxia, Gansu and Shaanxi. The second convergent club includes provinces such as Jilin, Hubei, Hunan, Jiangxi and Xinjiang. Only Yunnan and Sichuan appear in the third convergent club, while the last group consists of the remaining regions, i.e., Guangdong, Guizhou and Jiangsu.

Figure 6 shows a map of the results based on total factor productivity with the club convergence in China's regions from 1952 to 2008.

Figure 6: Map of club convergence across Chinese regions, total factor productivity 


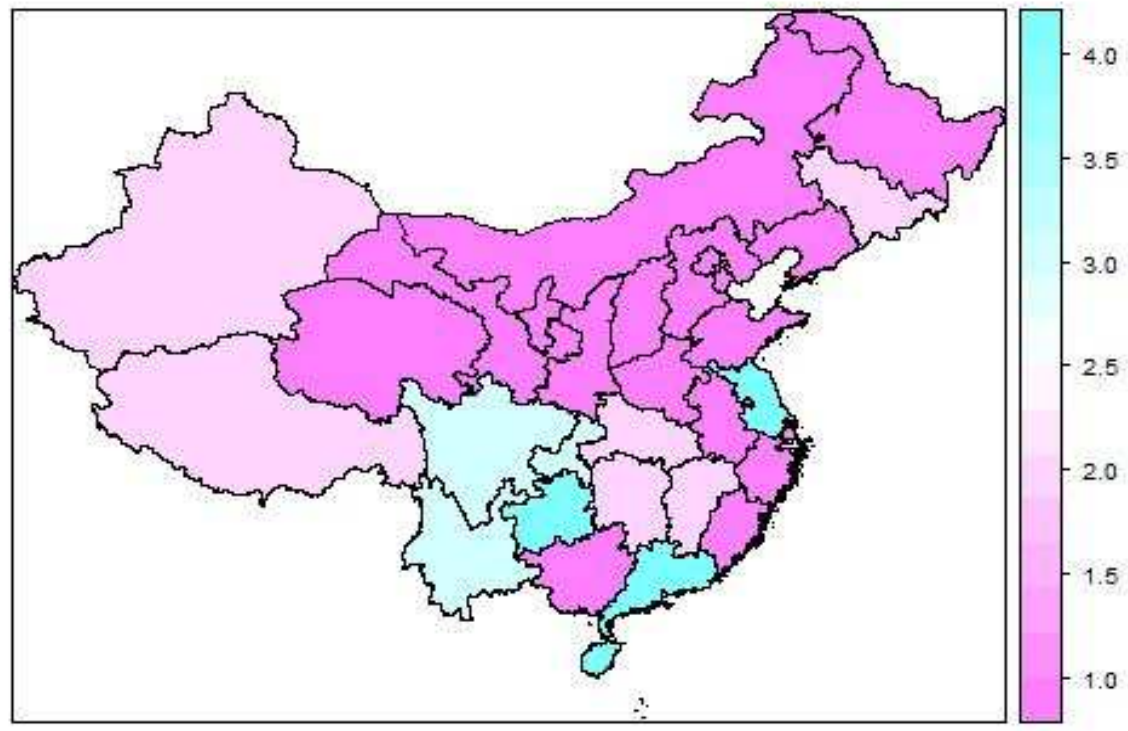

Note: 1 means club 1; 2, club 2; 3, club 3; and 4, club 4. See table below.

From the overall results it is possible to conclude that there has been a significant improvement in total factor productivity, since 18 regions now belong to the same group, which along with regions like Guangdong, Jiangsu and Guizhou represents an important cluster in the north and eastern part of China. Inland regions appeared clustered in another group, and these differences in TFP can probably be explained by the variation in per capita income and labor productivity. Furthermore, according to our results the trend is toward convergence, but first this convergence behavior happens within group of regions and second it is not the same for all the provinces. This result can be accounted for by the number of small clusters found. This phenomenon is observed especially in capital intensity and per capita income. From the economic policy point of view, although it is true that convergence occurs and it is related with economic geography and economic reforms carried out by the government, it is not altogether satisfactory. As more provinces join the same group, they should display a more homogenous behavior, where in theory standards of living, welfare and economic development improve. More effort is needed in regional economic development, especially in regions that diverge, but also in regions that are clustered with few provinces, since the desirable effect is that all provinces reach the same club.

Table 4: Convergence test, Total Factor Productivity

\begin{tabular}{|c|c|}
\hline Sub Club Convergence & Regions \\
\hline
\end{tabular}




\begin{tabular}{|c|c|c|c|}
\hline const & -1.002 & -11.256 & $\begin{array}{l}\text { Fujian, Guangxi, Heilongjiang, Shanxi, Anhui, Henan, Hebei, } \\
\text { Inner Mongolia, Qinghai, Ningxia, Gansu, Shaanxi. }\end{array}$ \\
\hline $\log t$ & -0.089 & -2.420 & \\
\hline \multicolumn{4}{|c|}{ Check whether the rest of the group forms the other convergent club: } \\
\hline & $\beta$ & t-stat. & \\
\hline const & 0.048 & 2.054 & \multirow{2}{*}{ Since $t$-stat $<-1.65$, repeat clustering procedures } \\
\hline $\log t$ & -0.593 & -61.861 & \\
\hline \multicolumn{4}{|r|}{ 2nd Convergent Club test } \\
\hline & $\boldsymbol{\beta}$ & t-stat. & \\
\hline const & -1.820 & -8.975 & Jilin, Hubei, Hunan, Jiangxi, Xinjiang \\
\hline $\log t$ & 0.388 & 4.651 & \\
\hline \multicolumn{4}{|c|}{ Check whether the rest of the group forms the other convergent club: } \\
\hline & $\beta$ & t-stat. & \\
\hline const & -0.208 & -3.723 & \multirow{2}{*}{ Since $t$-stat $<-1.65$, repeat clustering procedures } \\
\hline $\log t$ & -0.471 & -20.505 & \\
\hline \multicolumn{4}{|r|}{ 3rd Convergent Club test } \\
\hline & $\beta$ & t-stat. & \\
\hline const & -5.628 & -7.998 & Yunnan and Sichuan \\
\hline $\log t$ & 2.836 & 9.794 & \\
\hline \multicolumn{4}{|c|}{ Check whether the rest of the group forms the other convergent club: } \\
\hline & $\boldsymbol{\beta}$ & t-stat. & \\
\hline const & -3.493 & -7.101 & \multirow{2}{*}{ Since $t$-stat $>-1.65$, the rest form a convergent club } \\
\hline $\log t$ & 1.225 & 6.051 & \\
\hline \multicolumn{4}{|r|}{ 4th Convergence club } \\
\hline & & & ngsu, Guangdong and Guizhou \\
\hline
\end{tabular}

\section{Concluding Remarks}

There is a growing interest among economists in inequality and regional development across regions, where its spatial dimension plays a key role. Relatively recent developments on endogenous growth theory and new econometric techniques with a richer dataset are the main reasons underlying this interest. On the other hand, since the seminal paper by Paul Krugman (1991a,b) was published, a new line of research based on the so-called new economic geography has appeared, where the nature of the agglomeration of economic activities into clusters is investigated. The new growth theory and economic geography literatures are difficult to separate since they are closely linked to each other, and are a suitable framework in which to provide fresh developments on convergence behavior and regional growth.

In this context, the aim of this work is to analyze the existence of club convergence of per capita income, labor productivity, capital intensity and total factor productivity across Chinese regions over the period 1952-2008. With this aim, we applied a new panel data method that accounts for the heterogeneity of Chinese regions in a nonlinear time-varying 
framework. The advantage of this method compared with those used in the previous literature is that it allows us to identify regional clusters under technological heterogeneity. Knowing this, our work provides useful insights into the convergence process and the forces with a spatial dimension that work in that process. Policymakers can address specific economic policies on the identified clusters in order to guarantee the sustainability of regional growth and improve the standards of living of the Chinese population.

Our results indicate that regional clusters are important for the correct understanding of the convergence process across the Chinese economy. In particular, we found five regional clusters in the case of per capita income, with the most developed regions being located on the coast, followed by small clubs in the northern, central and western parts of China. However, on looking at the distribution of labor productivity, our results suggest that China's regions are divided into two convergent clubs. The first are located in the coastal area and the second in the central and western regions. These results are explained by the fact that economic activities, export strategy and foreign investment are mainly established in the coastal zone, thereby creating two distinct clubs, but with a substantially different degree of development between them. In contrast, divergence is found in the case of Heilongjiang, Guizhou and Liaoning.

Although the analysis performed in the case of per capita income and labor productivity is relevant, it should provide us with richer information if we examine capital intensity and total factor productivity in order to clarify the forces that drive regional development in the Chinese economy. The singular investment policy carried out by the Chinese government may account for the five convergent clubs that we found in the case of capital intensity. However, regions like Heilongjiang, Shanxi and Hebei are found to diverge. On the other hand, the results for total factor productivity indicate that there are four convergent clubs, the majority of the regions being located in one cluster and the others distributed among the smaller ones.

Overall, our findings suggest that previous works that examine convergence with panel data or unit root tests in time series analyses provide a limited explanation of the economic behavior of the Chinese regions, since regional clusters are important in understanding the complex regional growth in China. Nevertheless, it is also observed that some provinces are still diverging. On the other hand, our results indicate that there has been an improvement in the convergence process of total factor productivity, since 18 out of 28 provinces belong to the same group, which probably explains the club convergence observed in per capita income and labor productivity. However, stronger efforts are needed to develop specific economic policies on the regional capital intensity because a large number of clusters were found and only a small number of regions belong to each cluster. Policies oriented toward the development of productive infrastructure, human capital, and investment that has embodied technological progress may improve the current situation in the Chinese economy. These programs may be undertaken in a context where the market mechanisms work and where the whole population will benefit from these economic policies - especially those that display a lower degree of development. Finally, this paper provides empirical evidence that although convergence is achieved within groups of regions in the majority of the cases, from the regional development point of view this result does not satisfy the need to balance regional growth. The reason for this is that our results also suggest that China's regions are growing at different speeds, and thus creating small clusters instead of just one cluster that all the provinces belong to. More ambition and efficiency in the development of economic policies are needed, which may be supported at the microeconomic level with the intervention of medium-sized and small firms, local governments and other agents so that these policies will, in the end, be efficient 
in fulfilling the purpose that they were designed for. Experience has shown us that holding macro-packages in large firms and addressing the policies at a very centralized level causes inequality to persist, while regional growth remains unbalanced and the future growth of the whole nation becomes uncertain.

\section{References}

Acemoglu, D. Introduction to Modern Economic Growth. Princeton University Press. (2009)

Bai, C., Hsieh, C. and Qian, Y. The Return to Capital in China. NBER Working papers No 12755. (2006)

Bai, J. Inferential Theory for Factor Models of Large Dimensions, Econometrica 71 (2003),135-172.

Bai, J. Estimation Cross-Section Common Stochastic Trends in Nonstationary Panel Data, Journal of Econometrics 122 (2004),137-183.

Bai, J., and Ng, S. Determining the Number of Factors in Approximate Factor Models, Econometrica 70 (2002),191-221.

Bai, J. and Ng, S (2006): Evaluating Latent and Observed Factors in Macroeconomics and Finance, Journal of Econometrics 131: 507-537.

Baldwin, R. Agglomeration and endogenous capital. Processed, Graduate Institute of International Studies, University of Geneva. (1997)

Baldwin, R. and Martin, P. Agglomeration and Regional Growth. CEPR No. 3960. (2004)

Bernard, A.B. and Durlauf, S.N. Convergence in international outputs, Journal of Applied Econometrics 10 (1995), 97-108.

Bhalla, A., Yao, S., and Zhang, Z. Regional economic performance in China. Economics of Transition 11 (2003), 25-39.

Carlino, G. and Mills, L. Are US incomes converging? A time series analysis. Journal of Monetary Economics 32(1993), 335-346.

Cerrato, M., de Peretti, C., Larsson, R., and Sarantis, N. A nonlinear panel unit root test under cross section dependence. Discussion Paper. Department of Economics, University of Glasgow. (2008)

Chen, J., and Fleisher B.M. Regional Income Inequality and Economic Growth in China. Journal of Comparative Economics 22 (1996), 141-164.

Chow, G. Money and price determination in China, Journal of Comparative Economics 11 (1987), 319-333.

Chow, G. Are Chinese Statistics Reliable?, Cesifo Economic Studies 52 (2006), 396-414.

Cook, S. An alternative perspective on the stochastic convergence of incomes in the United States, Applied Economic Letters 15 (2008), 929-934.

Davis D.R. and Weinstein, D.E. Asearch for multiple equilibria in urban industrial structure. Working paper No.10252. National Bureau of Economic Research. (2004) 
Duranton, G., and Puga, D. "Micro-foundations of urban agglomeration economies". In: Henderson, J.V., Thisse, J.-F. (Eds.), Handbook of Regional and Urban Economics, vol. 4. Elsevier, Amsterdam, pp. 2063-2117. (2004)

Enders W. and Granger C.W. J. Unit root tests and asymmetric adjustment with an example using the term structure of interest rates, Journal of Business of Economic and Statistics 16 (1998), 304-312.

Fujita, M. Spatial Economics. Cheltenham: Edward Elger. (2005)

Fujita, M., Krugman; P. and Venables, A.J. The Spatial Economy. Cities, Regions and International Trade, Cambridge (Mass.), MIT Press. (1999)

Fujita, M., Krugman, P. The new economic geography: past, present and the future. Papers in Regional Science 83 (2004), 139-164.

Fujita, M. and Thisse, J.-F. Economics of Agglomeration, Cambridge, Cambridge University Press (2002)

Fujita, M-, and Mori T Transport Development and the Evolution of Economic Geography. Portuguese Economic Journal 4 (2005), 129-156

Fujita, M., Thisse, J-F Globalization and the evolution of the supply chain: who gains and who loses? International Economic Review. Forthcoming (2005)

Holz, C.A. OECD - China Governance Project: The Institutional Arrangements for the Production of Statistics", OECD Statistics Working Papers, 2005/1, OECD Publishing. (2005)

Henderson, J.V. (ed.) New Economic Geography. Cheltenham: Edward Elger (2005)

Herrerias, M.J., and Orts, V. The Driving Forces behind China's Growth, Economics of Transition 19 (2010) 79-124.

Herrerías, M.J., Orts, V. and Tortosa-Ausina, E. Weighted Convergence and regional clusters across China. Forthcoming in Papers in Regional Science. (2011)

Ho, C. and Li, D. Rising regional inequality in China: Policy regimes and structural changes, Papers in Regional Science 87 (2008), 245-260.

Islam, N. What have we learnt from the convergence debate? Journal of Economic Surveys 17 (2003), 309-362.

Jian, T., Sachs, J.D., and Warner, A.M. Trends in Regional inequality in China. China Economic Review 7 (1996), 1-21.

Kaldor, N. Essays on Economic Stability and Growth. London: Gerald Duckworth \& Co. Ltd. (1960)

Kaldor, N. Capital Accumulation and Economic Growth. F. A. Lutz, and D. C. Hague (eds.) in Theory of Capital, London: McMillan \& Co. Ltd., chap. 10, pp. 177-222. (1961)

Kanbur, R. and Venables, A.J. Spatial Inequality and Development. Oxford. (2005)

Kapetanios, G., Shin Y. and Snell A. Testing for a unit root in the non-linear STAR framework, Journal of Econometrics 112 (2003), 359-379.

Keung, C. and Lau, M. New evidence about regional income divergence in China, China Economic Review 21 (2010), 293-309 
Krugman, P. R. Increasing returns and economic geography, Journal of Political Economy 99 (1991a) 483-499.

Krugman, P. R. Geography and Trade. Cambridge: MIT Press. (1991b)

Lee, J. and Strazicich, M. Minimum LM unit root test with two structural breaks, Review of Economics and Statistics 85 (2003), 1082-1089.

Li, X. The Great Leap Forward, Economic Reforms, and the Unit Root Hypothesis: Testing for Breaking Trend Functions in China's GDP Data, Journal of Comparative Economics 28 (2000), 814-827.

Ma, H., Oxley, L. and Gibson, J. Gradual reforms and the emergence of energy market in China: Evidence from tests for convergence of energy prices, Energy Policy 37, (2009), 4834-4850.

Ma, H. and Oxley, L. The integration of major fuel source markets in China: Evidence from panel cointegration tests, Energy Economics 32 (2010),1139-1146.

Martin, P. and Ottaviano, G. Growth and agglomeration, Discussion Paper No. 1529, Centre for Economic Policy Research. (1996)

Matsuki, T. and Usami, R. Is Chinese provincial real GDP per capita nonstationary? Evidence from multiple trend break unit root tests, Department of Economics, Osaka Gakuin University. Mimeo. (2007)

$\mathrm{Ng}$, S. and Perron, P. Lag length selection and the construction of unit root test with good size and power, Econometrica 69 (2001), 1519-1554.

Oxley, L. and Greasley, D. A Time-Series Perspective on Convergence: Australia, UK and USA since 1870, The Economic Record 71 (1995), 259-270.

Ottaviano, G. and Puga D Agglomeration in the global economy: a survey of the 'new economic geography', World Economy 21 (1998), 707-731.

Ottaviano, G. and Thisse, J.-F. Agglomeration and economic geography". In: Henderson, J.V., Thisse,J.-F. (Eds.), Handbook of Regional and Urban Economics, vol. 4. Elsevier, Amsterdam, pp. 2563-2608. (2004)

Pedroni, P. and Yao, J.Y., Regional income divergence in China. Journal of Asian Economics 17 (2006), 294-315.

Perron, $\mathrm{P}$. and $\mathrm{Ng}$, S. Useful modifications to unit root tests with dependent errors and their local asymptotic properties, Review of Economic Studies 63, (1996), 435-465.

Phillips, P. and Sul, D. Transition Modeling and Econometric Convergence Tests, Econometrica 75 (2007), 1771-1855.

Phillips, P. and Sul, D. Economic Transition and Growth, Journal of Applied Econometrics 24 (2009),1153-1185.

Quah, D.T. Regional convergence clusters across Europe. European Economic Review 40 (1996c), 951-958.

Raiser, M. Subsidising inequality: Economic reforms, fiscal transfers and convergence across Chinese provinces. Journal of Development Studies 34 (1998), 1-26.

Rozelle, S. Rural Industrialization and Increasing Inequality: Emerging Patterns in China's Reforming Economy. Journal of Comparative Economics 19 (1994), 362-391. 
Sakamoto, H., and Islam, N. Convergence across Chinese provinces: An analysis using Markov transition matrix. China Economic Review 19 (2008), 66-79.

Smyth, R. and Inder, B. Is Chinese provincial real GDP per capita nonstationary? Evidence from multiple trend break unit root tests, China Economic Review 15 (2004), 1-24.

Venables, A. J. Equilibrium locations of vertically linked industries. International Economic review 37 (1996), 341-359.

Wang, Z. Regional Divergence of per capita GDP in China: 1991-99. Journal of Chinese Economic and Business Studies 2 (2004), 39-53.

Weeks, M. and Yao, J.Y. Provincial Conditional Convergence in China, 1953-1997: A Panel Data Approach. Econometric Reviews 22 (2003), 59-77.

$\mathrm{Wu}, \mathrm{Y}$. The role of productivity in China's growth: new estimates, Journal of Chinese Economics and Business Studies 6 (2008), 141-156.

Yao, S. and Zhang, Z. On Regional Inequality and Diverging Clubs: A case Study of Contemporary China. Journal of Comparative Economics 29 (2001a), 466-484.

Yao, S. and Zhang, Z. Regional Growth in China under Economic Reforms. Journal of Development Studies 38 (2001b), 167-186.

Zhang, Z., Liu, A. and Yao, S. Convergence of China's regional incomes 1952-1997, China Economic Review 12 (2001), 243-258. 